\title{
Transnational Science Guanxi: A Necessary, but Insufficient, Condition for Sino-Danish Flows of Knowledge, Talent and Capital in Genetics
}

Rasmus Gjedss $\varnothing$ Bertelsen (UiT, AAU, Rasmus.Bertelsen@uit.no), DU Xiangyun (AAU) \& Morten Karnøe

Søndergaard (AAU)

Abstract: Genetics is observed as a particularly active field of Sino-Danish science collaboration, brain circulation and funding. Explaining the level of activity of this scientific field is therefore valuable for understanding the conditions allowing such activity. This paper identifies Danish scientific excellence as a necessary, but insufficient, condition. This condition becomes sufficient together with another necessary, but insufficient, condition, which is Sino-Danish transnational science guanxi, or networks and acquaintanceship. This guanxi is based on the previous graduate studies of Chinese in Denmark, or brain circulation. The paper finds that brain circulation in the form of graduate students can have revolutionary long-term effects on Sino-Danish science collaboration and investments, exemplified in the location of Beijing Genomics Institute Europe in Copenhagen.

\section{Introduction: the Necessity of International Science Collaboration for}

\section{both China and Denmark}

China and Denmark at different levels of development and relative wealth are both highly dependent on either becoming (in the case of China) or developing as innovative, knowledge-based economies (the case of Denmark). Science, technology and innovation are, therefore, of great importance for both societies. International flows of knowledge, talent and capital are key to the development of science, 
technology and innovation in both countries. Life science and genetics are central for attaining national ambitions of innovative, knowledge-based economies, which produce goods and services of high value creating high-paying jobs. It is therefore important to understand the necessary and sufficient conditions for such transnational science collaboration, talent circulation and funding in genetics between academia, pharmaceutical and life science industry, and public and private funding bodies as research councils and foundations.

Genetics is a field of particularly strong Sino-Danish flows of knowledge, talent and capital between academia, business, government and philanthropy contributing to the development of life science and industry in both countries. The field can, therefore, illuminate under what conditions such strong flows of knowledge, talent and capital between academia, business, government and philanthropy can be established between a small, Nordic, highly developed economy (Denmark) and the giant emerging economy of China.

Initially, this paper will discuss the importance of international science collaboration and brain circulation for both China and Denmark at their different levels of development. On this basis, the paper turns to analyzing in depth Sino-Danish flows of knowledge, talent and capital in the field of human genetics. This analysis will show the crucial role of deep, personal relationship between leading Danish and Chinese scientists for long-term effects on questions of science collaboration, talent recruiting, funding and investment. Therefore the article applies the term 'guanxi', since that Chinese term for relations or connections and its importance in Chinese society is well known. There is a significant literature on the importance of guanxi in Chinese business and society (see, for instance, Dana 2014, Gao 2014, Kuah-Pearce, Rezaei \& Schøtt 2014). However, guanxi in transnational natural science and technology relations between China and the outside world has received very little attention (Zhang 2015), which this article seeks to contribute to. 
It will show how even a small, Nordic country can become deeply embedded in science collaboration, talent circulation and investment with China based on early creation of transnational science guanxi. This guanxi is a necessary, but in itself insufficient, condition. Danish scientific quality is also a necessary, but insufficient, condition. Together, guanxi and Danish scientific quality makes these flows of knowledge, talent and capital possible. The structural conditions for these flows are the following: the highly developed, small state Denmark is more motivated for collaborating with the emerging scientific and otherwise great power of China, than China is to work with Denmark. China is in absolute numbers a much greater science player than Denmark and has much greater resources and talent pool.

\section{China: the Role of International Science Collaboration and Brain Circulation for Creating a Sustainable, Innovative, Knowledge-Based Economy}

China has enjoyed unprecedented economic growth since opening the country to the world in the late 1970s. This growth has been based on an almost unlimited supply of cheap labor for export-orientated manufacturing. This manufacturing destined for export has gradually moved production into more sophisticated products, moving from, for instance, textiles, to electronics and office equipment (Huang, Gouveia \& Varum 2007). However, this growth model has created great social and regional imbalances between groups in society and between regions of China. This growth model is neither socially nor

environmentally sustainable. So the Chinese leadership is keenly aware of the need to build a knowledge-based innovative economy, and pursues a range of science and technology and research and development policies with this aim (Huang, Gouveia \& Varum 2007, Cao, Suttmeier \& Simon 2009, Lundvall et al. 2009, Schaaper 2009). Initially, China pursued the 'technology for markets' policy demanding technology transfer to China by foreign companies in exchange for market access. This policy has, however, not been very successful. China has become the home to much high-tech manufacturing in typically information and communications technology, but this is predominantly taking place in 
subsidiaries of foreign firms. China remains highly dependent on foreign technology, and Chinese manufacturers pay dearly for technology licenses out of slim profit margins (Huang, Gouveia \& Varum 2007, Cao, Suttmeier \& Simon 2009).

The Chinese leadership understands that science, technology, innovation, research, and development are central for creating a new and sustainable model for economic growth. This understanding is clear from 'National Guidelines for Medium- and Long-Term Plans for Science and Technology Development (2006-2020)'. This plan commits China to 'indigenous innovation' (zizhu chuangxin) (Cao, Suttmeier \& Simon 2009). Transnational flows of knowledge, technology and investment through the movement of highly-qualified individuals are central to this policy. Both Chinese and foreign science, technology and innovation policy is often focused on facilitating such flows and networks. Brain circulation in the shape of returned Chinese scientists, engineers and financiers play a central role in the development and growth of Chinese science, technology, and innovation (Saxenian 2005, Saxenian 2006, Saxenian, Sabel 2008, Zweig, Changgui \& Rosen 2004, Zweig 2006, DeVoretz, Zweig 2008, Wang, Zweig \& Lin 2011).

International exchange and brain circulation have played important parts in Chinese scientific and societal development policy since the late 1800 s. The imperial government sent students to Europe, the USA and Japan in the late 1800s and early 1900s. These individuals had great influence on Chinese technology and society. China was also the home of a significant number, around 20, predominantly American missionary colleges, universities, medical schools and law schools in the early 1900s until they were nationalized at the outset of the Korean War. These missionary institutions were 'broadband' connections to American society and academia(Bertelsen, Møller 2010, West 1976, Lutz 1971). In addition, a large number of Chinese students studied at universities in the USA. Even after the PRC-US confrontation in the Korean War did Chinese graduates in the USA return to the Chinese mainland (Wang ). In the 1950s, China turned to the USSR and sent many students to the USSR and received 
Soviet specialists until the break between the two countries(Bernstein 2010). Denmark also exchanged students with China in the 1950s and early 1960s according to the cultural agreement between the two countries. This exchange was on a very small scale in absolute terms, but had significant effects on Danish Sinology and China area studies (Kure, Rasmussen \& Bechsbøft ). ${ }^{1}$ China only stopped using international scientific collaboration and brain circulation for developmental purposes during the Cultural Revolution.

After the Cultural Revolution, China started sending students abroad and receiving them around 1973, and with the opening in the late 1970s the numbers expanded rapidly. More than a million Chinese have studied abroad, mainly in the USA, and there were, for example, 274,439 Chinese students in the USA in the academic year of 2013-2014. Most of these students are graduate students, testifying to their level of skills and talent (Institute of International Education 2011, Institute of International Education 2014).

Most of these Chinese students and fellows remained overseas, especially in the USA, after graduating or ending their fellowships. This trend reflected lack of opportunity and personal and professional freedoms in China, better opportunities in the West, and political circumstances in China, accentuated by the events on Tiananmen Square. The tide began to turn with increased liberties to settle and work at will at home, better professional opportunities and political assurances of the rights to enter and leave China at will(Zweig 1997, Zweig, Changgui \& Rosen 2004, Zweig 2006, DeVoretz, Zweig 2008, Wang, Zweig \& Lin 2011).

Returned Chinese graduates and scholars, 'Hai Gui' or 'sea turtles', have since the late 1800 s contributed significantly to the development of Chinese science and technology transferring knowledge, as will also be clear in this paper. The importance of these 'sea turtles' is clear from the great efforts expended by Chinese universities, cities and region to attract them back. 'Sea turtles' are offered higher salaries,

\footnotetext{
1 Interview.
} 
research funding, investment capital, residence permits, loans for cars and homes (Zweig 1997, Zweig, Changgui \& Rosen 2004, Zweig 2006, DeVoretz, Zweig 2008, Wang, Zweig \& Lin 2011, Saxenian , Saxenian 2005, Saxenian 2006, Saxenian, Sabel 2008).

Overseas Chinese played central roles in developing the Chinese manufacturing economy through investments. Taiwanese and later Chinese expatriate scientists, engineers and financiers in the USA have played key roles in transferring technology to first Taiwan and subsequently China to create the electronics manufacturing and increasingly design ecosystems in China. AnnaLee Saxenian's work shows that brain circulation by Taiwanese and Chinese graduate students in science and technology with professional experience from Silicon Valley or Taiwanese and Chinese lawyers and bankers in the USA have been central in creating high-tech manufacturing in first Taiwan and then China. Such Taiwanese and Chinese expats have created dense networks of knowledge and capital between Silicon Valley, Taiwan and China (Saxenian 2005, Saxenian 2006, Saxenian, Sabel 2008).

The well-described importance of flows of knowledge, talent and capital between academia, business and finance between China (and Taiwan) and the USA raises the question of the possibility and effects of brain circulation between Denmark and China. The necessary and sufficient conditions for such circulation of talent, science and funding are the topic of this article.

\section{Denmark: the Role of International Science Collaboration and Brain}

\section{Circulation for Maintaining Scientific and Economic Competitiveness in a}

\section{Small, Highly Developed Country}

Danish scientific and economic competitiveness is also dependent on international science collaboration and brain circulation. Danish science policy-makers are increasingly aware of this importance. There is growing science policy awareness that a very small share of global knowledge is produced in Denmark (1-2 \% based on publications) and it is, therefore, necessary to collaborate internationally. There is also 
growing acknowledgement that large emerging countries as China play an increasingly important role in international science and that Denmark must collaborate with them. This recognition is illustrated by a number of Danish science policy programs: The International Network Program of the Danish Agency for Science, Technology and Innovation with Brazil, China, India, Israel, Japan, South Korea, and the USA; science, technology and innovation outposts in the shapes of Innovation Centers in Silicon Valley, Munich and Shanghai; and strategic investments in Sino-Danish research and educational collaboration, such as the Danish National Science Foundation-National Science Foundation of China research centers and the Sino-Danish Center at the University of the Chinese Academy of Sciences. (Ministry of Higher Education and Science 2013) However, the partnerships identified in this paper reach further back in time. These partnerships show the importance of early engagements, and deep, long-term collaborative partnerships for building transnational science guanxi. The finding of this article is that the guanxi built from such deep, long-term partnerships is a necessary, although insufficient, condition for intense SinoDanish science collaboration, talent circulation and funding.

Denmark is a small, open economy with a high cost level. ${ }^{2}$ The Danish political economy is characterized by market capitalism, a highly unionized labor market and a tax-financed universal welfare state. Such an economy depends on high labor-market participation, high productivity and large exports. The very short 1900s socio-economic history of Denmark is that it developed from an agricultural economy with strong exports to an industrial economy with many small and medium-size enterprises often exporting and finally to a service-based economy with a significant innovation and knowledge component. Thre have been and remain to be demographic and employment challenges to the Danish economy. Initially farm-workers moved to industry in urban areas. Subsequently, much low-skilled manufacturing and assembling work moved to low-wage countries. Enlargement of the European Communities in 1986 with Spain and Portugal first made it possible to move such jobs to Southern Europe. The fall of the Iron

\footnotetext{
${ }^{2}$ For an introduction to Danish economic history, see (Henriksen 2006)
} 
Curtain and the reunification of Europe made it attractive to move such jobs to Eastern and Central Europe. The opening of China in the late 1970 s and globalization moved many such jobs to East Asia. For a time, the Danish government thought the solution was raising education-levels in Denmark, "to become smarter, when the others become cheaper" (Statsministeriet ndb, Statsministeriet nda). However, the Danish government and scientific leaders in academia and industry became acutely aware of the rapid scientific rise of China around 2007 and the competition China could also supply in fields of science, technology, and innovation(Bertelsen, Du \& Søndergaard 2014). This realization led to ambitious Danish science policy vis-à-vis China after 2008 with most notably the establishment of the Sino-Danish Center at the University of the Chinese Academy of Sciences. ${ }^{3}$ The future of Denmark as an affluent, highly developed society is therefore deeply dependent on the country finding a privileged position in an integrated global, knowledge-based economy. Here it is important to note that research demonstrates that the Danish companies with most international research and development and the most internationally integrated research and development also have the highest growth in research and development in Denmark (Wiegand 2011).

Sino-Danish science collaboration and brain circulation is, therefore, important to the future of Danish society and economy. This brain circulation will be central to creating integrated networks of innovation, knowledge-production, investment, manufacturing and sales between Denmark and China. This brain circulation can supply highly educated Chinese and Danish individuals with networks and deep knowledge and understanding of the other society, its academia and its business for creating such integration. The knowledge and networks of Chinese alumni can reduce transaction costs for Chinese investments in Denmark, which will be increasingly important to Danish socio-economic development in the future, as is clear in the field of genetics.

\footnotetext{
3 This Danish realisation and policy response towards China is described and analysed in (Bertelsen, Du \& Søndergaard 2014)
} 
As is found in the interviews behind this paper, Denmark is at a disadvantage qualitatively and quantitatively compared to especially the USA for fostering brain circulation with China. Denmark is

much less well-known than the USA, Danish education and research are much less prestigious and attractive, and much fewer people are engaged and deeply knowledgeable about Denmark. These handicaps all emphasize the importance of early key individuals as YANG Huangming, who leads to a chain of brain circulation between the two countries.

The paper now turns to analyzing the strong flows of knowledge, talent and capital between academia, business, government and philanthropy in Denmark and China for identifying the necessary and sufficient conditions for these flows.

\section{The Background: Sino-Danish Brain Circulation}

Sino-Danish brain circulation exhibits an early and very successful example, which introduces the importance of such circulation for innovation and sustainable growth in Denmark, the case of Dr. VAN Sai-Chiu, the founder of the Danish food manufacturer Daloon. VAN Sai-Chiu arrived in Denmark in 1935 to study Danish agricultural organization and technology. He stranded in Denmark because of the Japanese attack on China in 1937 and entered the same year the Royal Veterinary and Agricultural College in Copenhagen, from which he graduated with a PhD in microbiology in 1946. Copenhagen was at the time an international center for biotech and nutrition research(Kragh 2001). He worked in Danish biotechnological and pharmaceutical industry before founding the manufacturer of Asian food, Daloon, in 1960, which became a very successful business. (RW.ERROR - Unable to parse:) (RW.ERROR - Unable to parse: ) (RW.ERROR - Unable to parse: ) (RW.ERROR - Unable to parse: ) (RW.ERROR - Unable to parse: ) Dr. VAN Sai-Chiu is a valuable case for introducing the nexus between Sino-Danish brain circulation, higher education in Denmark for Chinese students, cultural brokerage and successful 
entrepreneurship, which receives much policy attention today, 80 years after VAN Sai-Chiu's arrival in Denmark (Tamm 2009, Larsen 2009).

Denmark recognized the People's Republic of China in 1950, and the two countries exchanged students beginning in the 1950s on a small scale, but important for Danish sinology. This exchange was interrupted by the Cultural Revolution, but resumed in 1973. The exchange of students under a cultural agreement (which was not signed until 1981) played an important part in the modernization and development of Danish Sinology and China area studies in Danish universities. Sinology in the University of Copenhagen had originally been classical, focusing on classical Chinese language, philosophy and literature. The experiences of Danish Sinology students in China in the 1950s and again in the 1970s equipped and motivated these students to transform Danish Sinology into the study of modern Chinese language and society and to teach these subjects at Danish universities. The Danish Sinology students who spent time in China in the 1970s are the leading professors of Sinology and Chinese area studies at Danish universities today. They have played key roles in forming and training subsequent generations of Danish graduates in Sinology and China area studies, which have supplied important human capital for an ever expanding commercial, political, cultural and educational relationship between Denmark and China. $^{4}$

When China started to send students abroad on a large-scale from the late 1970s and in the 1980s, Denmark also benefitted from this, although nowhere near the USA even on a relative scale. China originally focused on sending students to Denmark in sciences and technology, switching later to social sciences and humanities. ${ }^{5}$

\footnotetext{
4 This paragraph is based on interviews with senior Danish Sinologists and China area studies scholars for their experiences in China in the 1970s and later professional development in Danish academia.

${ }^{5}$ Interviews with leading Danish Sinologists
} 


\section{A Fruitful Encounter: YANG Huangming and Lars Bolund, Path-Breakers}

\section{in Sino-Danish Genetics Collaboration}

One such Chinese graduate student sent to Denmark was YANG Huangming, which would have profound consequences for Sino-Danish science collaboration and brain circulation in genetics. YANG Huangming had graduated with a B.Sc. from Hangzhou University in 1978 and a Master's degree in biology from Nanjing Railroad Medical Institute (now Southeast University) in 1982. In the mid-1980s, he was selected to go to the University of Copenhagen to study a PhD at the Institute of Medical Genetics. Here at the Panum Institute complex of the University of Copenhagen, he met a young Swedish professor of medical genetics at Aarhus University, Lars Bolund. Lars Bolund tells the story that he had travelled to Copenhagen to give a Steno symposium lecture, and after the lecture this Chinese PhD student approached him, and they struck up a conversation. YANG Huangming was completely unfamiliar with Denmark and was looking for guidance. Lars Bolund became the co-supervisor of YANG Huangming after this meeting. This chance encounter would have profound effects on Sino-Danish science collaboration and brain circulation in genetics. Lars Bolund had an existing interest in China, since he had been fascinated by Chinese history, philosophy and politics since childhood.

Around 1988, Lars Bolund and YANG Huangming were very involved with the Sino Danish Biomedical Postgraduate Training Center in Beijing. The Center was sponsored by the Danish International Development Agency (DANIDA) and worked closely with Aarhus University, University of Copenhagen and the Danish National Institute for Health Data and Disease Control (Statens Serum Institut). This center trained hundreds of Chinese medical doctors and biomedical researchers, of which three became academicians of the Chinese Academy of Sciences. However, the Tiananmen Square incident on 4 June 1989 put limitations on this Sino-Danish collaboration when Denmark together with the rest of Europe imposed sanctions on China (Jensen 2002). 
After finishing his Copenhagen PhD in 1988, YANG Huangming did postdoctoral work first between 1988 and 1990 at the Centre d'Immunologie de Marseille-Luminy of the Institut national de la santé et de la recherche médicale and Centre national de la recherche scientifique, one of Europe's leading centers in immunology. He continued postdoctoral work between 1990 and 1994 at Harvard Medical School and University of California, Los Angeles. YANG Huangming, thus, became exceptionally familiar with Scandinavian, European and American medical science at the highest level. What follows is the story of how YANG Huangming assisted by Lars Bolund brought China into international genetics at the highest level in the Human Genome Project while creating the Beijing Genomics Institute, which is today the world's largest genetic sequencing organization. YANG Huangming and Lars Bolund simultaneously maintained and developed strong Sino-Danish linkages and flows of knowledge, talent and capital in genetics, which is treated subsequently.

\section{Bringing China into Global Genetics: the Human Genome Project}

The United States Department of Energy started the Human Genome Project formally in 1990 together with the National Institutes of Health to map the human genome. The project came to include partners from Britain, China, France, Germany, and Japan. YANG Huangming, assisted by Lars Bolund, played a key role in getting China into this project and therefore into the core of global genetics research. As early as 1993, YANG Huangming and Lars Bolund were lobbying global and Chinese science for China to be included in the project. Western scientists responded favorably, while the Chinese official interest curiously was more limited. YANG Huangming returned to China in 1994 with this aim of getting China into the Human Genome Project. YANG Huangming's thinking was to apply large-scale, low cost high efficiency to genetic sequencing inspired by Chinese manufacturing. His instrument was going to be the Human Genome Center of the Chinese Academy of Sciences. In 1998, there was a sudden opportunity to 
become part of the Human Genome Project, but the Chinese Academy of Sciences did not provide the optimal flexibility and resources. ${ }^{6}$

Therefore, in 1999, YANG Huangming founded the Beijing Genomics Institute (BGI) as a private nonprofit research organization. BGI was placed in an industrial zone near Beijing International Airport, where it received free premises. Money came from the Chinese Academy of Sciences and YANG Huangming's hometown, but it was also to a large extent borrowed counting on the future success of the project. The Chinese Academy of Sciences also designated the Beijing Genomics Institute as its Genomics and Bioinformatics Institute. In September 1999, YANG Huangming promoted the idea of the Beijing Genomics Institute as a partner of the Human Genome Project at the $5^{\text {th }}$ International Strategy Meeting on Human Genome Sequencing. Subsequently, the Chinese Academy of Sciences decided to fund sequencing $1 \%$ of the human genome, with the Beijing Genomics Institute doing over half of the Chinese effort.

When the result of the Human Genome Project was presented by President Bill Clinton and Prime Minister Tony Blair in 2001, China was mentioned as contributor. Also at this time, the Beijing Genomics Institute published in the journal Nature. From the Clinton-Blair mentioning, President JIANG Zemin discovered China's participation in the Human Genome Project, which he had been unaware of. The highest political leadership in China located and visited the Beijing Genomics Institute, and JIANG Zemin received the institute's leadership. This high-level political interest in the Beijing Genomics Institute kickstarted its activities and fundraising, but also led to problems with the Chinese academic world. The Chinese Academy of Sciences activities were, therefore, separated from commercial sequencing in the Beijing Genomics Institute working as a private non-profit research organization.

\footnotetext{
6 The narrative on BGI is based on conversation with leading Danish geneticists and these accounts and websites (Normile, Yimin \& Pennisi 2002, BGI nd, Larson 2013, Specter 2014)
} 
The high-level political interest led to much publicity in China and competition between localities to attract the Beijing Genomics Institute. Shenzhen made a very attractive offer of building a large, free facility and biobank. This support has made it possible for the Beijing Genomics Institute to expand dramatically to 4000 employees. Other localities have also offered support, and the institute now has facilities in several places in China and abroad. BGI Europe placed in Copenhagen is of particular interest and is discussed in detail below.

BGI Hong Kong was established in March 2009 as the first branch of the Beijing Genomics Institute outside Mainland China. BGI Hong Kong was set up to benefit from the legal environment and transportation and scientific infrastructure of Hong Kong, which greatly facilitates the movement of genetic samples(BGI 2012d). In 2010, the Beijing Genomics Institute established BGI Americas in the academic capital of North America, Cambridge, MA, MA, which is also home to the Broad Institute, a joint institute of Harvard University and the Massachusetts Institute of Technology. BGI Americas works together with American universities, hospitals and pharmaceutical industry, such as Merck. The Beijing Genomics Institute works with 17 of the world's 20 largest pharmaceutical companies(BGI 2012a). Also in 2010, BGI Europe was founded in Copenhagen, which is the topic of detailed discussion below(BGI 2012c). Late 2010, BGI founded BGI-Asia Pacific to work with areas such as Southeast Asia, Korea, South Asia, the Middle East and Oceania. The Asia-Pacific outreach has led to collaboration with University of Melbourne to sequence the draft genome of Ascaris suum, a parasitic roundworm of pig, and collaboration with Lal Teer Livestock Ltd in Bangladesh on the water buffalo genome (BGI 2012b). Also late 2010, BGI Japan was founded in Kobe to provide hardware and software services to Japanese research and facilitate Sino-Japanese collaboration and exchange (BGI 2012e). 


\section{BGI Europe-Sino-Danish Networks and Investments in Genetics}

As mentioned above, BGI has established branches in the major science nations: the USA and Japan. It is natural that the Beijing Genomics Institute would also establish itself in Europe, but it is more puzzling that it would choose to do so in the small state of Denmark. The Beijing Genomics Institute could have established itself in Britain, France or Germany, which were all partners in the Human Genome Project. For instance, it could have chosen Cambridge, UK, which is home of the Welcome Trust Sanger Institute.

Interview data from leading Danish geneticists suggest that the decision to locate in Denmark is inextricably linked to YANG Huangming's PhD studies in Copenhagen and close links to Danish genetics research and individuals. Networks and acquaintanceships play an important role in Chinese culture, and YANG Huangming has deep roots in Denmark and close connections to especially Lars Bolund. This connection is illustrated by that Lars Bolund is on the Beijing Genomics Institute Advisory Board with very prominent international geneticists. Lars Bolund is a former or current honorary professor at the Chinese Academy of Sciences (Human Genome Center), Chinese Academy of Medical Sciences (Peking Union Medical College), Beijing Institute of Genomics (Chinese Academy of Sciences) and Hainan Medical College. Lars Bolund has been honored with the Chinese National Friendship Award in connection with the 60 year anniversary of the People's Republic of China, an honor which has given him access to decision-makers at the highest level in China.

YANG Huangming and BGI have sent many graduate students to both Aarhus University and University of Copenhagen, who have returned to BGI, as is discussed below. A necessary condition for the BGI investment in Denmark is the quality of Danish science and medicine in terms of clinical data, stringent diagnostics, biobanks, cohort studies, and thorough family and medical records. However, interviews with Danish and Chinese geneticists indicate that scientific quality is not a sufficient condition for SinoDanish collaboration. 
The BGI Europe facility in Copenhagen and computing center in Aarhus represents an investment of around 70 mio DKK (10 mio USD or 9,4 mio EUR). In addition, there is large BGI Europe support to joint research projects, which is described in greater detail below. BGI Europe has become an integrated part of a closely knit network of universities, life science and pharmaceutical companies, public and private foundations both in Denmark and China providing large grants for genetic research. This network is the key to understand flows of knowledge, talent and capital between Denmark and China in genetics.

In Denmark, the members of this network are Aarhus University and the University of Copenhagen, the Technical University of Denmark, the then Danish National Advanced Technology Foundation, the Danish National Science Foundation, the Danish Council for Independent Research, the Lundbeck Foundation, the Novo Nordisk Foundation, Novo Nordisk, Leo Pharma and the Danish Bacon \& Meat Council. The Chinese partners are overwhelmingly the Beijing Genomics Institute, and to much less extent the National Science Foundation of China and national and local authorities, the latter which try to attract high-tech activities to their regions. The European Union is also a player supporting European research projects and networks, which this Sino-Danish research is part of.

The overall pattern is large joint Sino-Danish research centers sponsored by public and private Danish foundations with significant in-kind support from the Beijing Genomics Institute. There is much less significant and much rarer support from the National Science Foundation of China. The partnership is usually between Danish universities and the BGI providing very important in kind support in gene sequencing and bioinformatics. These centers are the major venues for bringing together usually senior Danish and junior Chinese scientists and for bringing Chinese graduate students to Denmark.

The Danish National Science Foundation is cosponsoring 10 basic science research centers together with the National Science Foundation of China. Of these centers, the Sino-Danish Center for Breast Cancer research is of interest here with its BGI involvement and YANG Huangming as Chinese co-director. The 
Danish National Science Foundation has in total awarded 22.7 mio DKK (3.2 mio USD, 3 mio EUR) to this center (Danish National Research Foundation nd, Sino-Danish Breast Cancer Research Centre nd).

The Lundbeck Foundation has made a donation of 60 mio DKK ( 8.5 mio USD, 8 mio EUR) to the project LUCAMP, Lundbeck Foundation Centre for Applied Medical Genomics in Personalised Disease Prediction, Prevention and Care. It is presented as an explicitly Sino-Danish initiative, which aims to read the human genome and the gut microbiome to improve metabolic and cardiovascular health of at-risk populations. This project is directed by senior Danish scientists working closely with BGI Europe supplying genetic sequencing and bioinformatics. ${ }^{7}$

Knowledge, talent and capital flow across the borders between human, veterinary and plant genetics. Denmark has a strong veterinary and agricultural tradition in especially pig breeding. This knowledge is the basis of Sino-Danish veterinary and agricultural knowledge collaboration which is outside the scope of this paper. However, pigs are very important model animals for human health research. Therefore, a consortium consisting of Göttingen Ellegaard Minipigs, Aarhus University, the University of Copenhagen and the Beijing Genomics Institute have formed the private company Pixiegene to commercialize novel genetic porcine models of human decease (Pixiegene).

The Lundbeck Foundation Initiative for Integrative Psychiatry, IPSYCH, is based on an initiatial 121 mio DKK grant in 2012 and a follow-up grant in 2015 of 120 DKK (total 34 mio USD, 32 mio EUR) for multidimensional studies of schizophrenia, bipolar, depression, autism and ADHD. The project is anchored at Aarhus University in partnership with the Danish National Institute for Health Data and Disease Control (Statens Serum Institut), BGI, deCODE Genetics in Iceland and the Faroese Biobank. ${ }^{8}$

\footnotetext{
7 Interviews and (LuCamp nd)

${ }^{8}$ Interviews and (iPsych 2015)
} 
It is clear from this network pattern of universities, public and private research funders and business in Denmark and China, that the funding and science has predominantly been Danish. The net contributors of knowledge and capital have been Danish, while the contributor of talent has been China. However, expert participants testify that the Chinese side is catching up knowledge-wise very fast and is set to surpass Denmark soon.

\section{The Experiences and Motivations of Chinese Genetics Graduate Students}

\section{and Fellows in Denmark}

What stands out from interviews with Chinese graduate students and postdocs in Denmark is the importance of human networks in global science. There may be a tendency to believe that talent flows freely and rationally in global science. However, our interview data and additional observations suggest that there are important elements of path-dependency in the trajectories of global talent in science.

What we observe in interviews with Chinese PhD students and postdocs in Denmark is that Sino-Danish talent circulation in terms of recruiting Chinese graduate students to Denmark is based on two avenues. There is a trajectory, where Chinese graduate students are attracted to Denmark based on the publications of potential supervisors and without previous acquaintanceship with Denmark. This trajectory may constitute an 'ideal typical' science recruitment path.

However, what we observe to a great extent is a path-dependent trajectory where previous Sino-Danish personal science networks play a key role in the recruitment of Chinese graduate students to Danish genetics. YANG Huangming and BGI are key factors here. As mentioned earlier, Denmark is at a disadvantage to promote brain circulation with China compared to most clearly the USA. Danish higher education and science is much less well-known and prestigious than top American universities, and there are much fewer Chinese scientists with a Danish background than American. But the Chinese 
scientists with Danish education background play a key role for Sino-Danish brain circulation. Interviews with Chinese graduate students and postdocs in Denmark show that American or Anglo-Saxon graduate education was the first priority for exceptionally talented Chinese undergraduates. However, the advice of university professors and/or mentors with a Danish educational background within BGI guided young Chinese to pursue graduate studies in Denmark. These graduate studies in Denmark were sometimes following work for BGI in Denmark. Three to four such generations of mentor/mentees among Chinese graduate students of genetics in Denmark seem distinguishable tracing back to YANG Huangming. Wellestablished Sino-Danish networks in science appear crucial for the continued recruitment of outstanding Chinese science talent to Denmark in light of the clear message from Chinese PhD students and postdocs in Denmark, that American or other Anglo-Saxon graduate education is the first and obvious choice for outstanding Chinese undergraduates.

\section{Conclusion: the Necessary and Together Sufficient Conditions for Sino-}

\section{Danish Brain Circulation in Genetics}

China is dependent on transnational flows of knowledge, talent and capital for developing into a sustainable, innovative knowledge-based economy, where the circulation of talent between China and especially the USA and its effects are well-described by AnnaLee Saxenian, David Zweig and others. Denmark is also dependent on international science collaboration and brain circulation to maintain and grow level of prosperity and welfare. With the growth of science in emerging countries, as in China, Sino-Danish flows of knowledge, talent and capital between academia, business and philanthropy will be important for Danish scientific and business competitiveness. However, these flows between Denmark and China have not been described or analyzed in detail. Genetics is a field characterized by circulation of science, talent and capital between academia, business, government and philanthropy in Denmark 
and China. Genetics is, therefore, an important case to look at for understanding the conditions and actions that can promote such flows between Denmark and China.

It is clear from our interview-based analysis of Sino-Danish science cooperation, circulation of talent and public-private-philanthropic funding in genetics, that there are two individually necessary and together sufficient conditions for such collaboration: first Danish scientific and medical excellence and second high-level Sino-Danish transnational science guanxi. The structural context for this Sino-Danish knowledge collaboration and brain circulation is that the small state of Denmark can be assumed to be motivated to engage with China as a very large country with enormous resources and talent. However, Chinese motivation for engagement with the small state of Denmark (as compared to a large, developed country) has to be explained.

The first necessary, but individually insufficient condition is high quality Danish science and medicine in terms of clinical data, stringent diagnostics, biobanks, cohort studies, and thorough family and medical records. Scientific quality as a necessary condition for scientific collaboration, talent recruitment and funding is to be expected. However, our study suggests that such scientific quality is insufficient to explain the level of Sino-Danish genetic research interaction given the strong pull of especially American top universities.

The other condition, transnational science guanxi, is more surprising and interesting, as it seems 'irrational'. Flows of scientific knowledge, talent and resources should ideally be based solely on scientific quality and publications and not on personal acquaintanceships. This guanxi is the deep and long-term personal relationships between leading Danish and Chinese geneticists built on the graduate student experiences of the Chinese parties in Denmark and decades of collaboration afterwards. This condition can be culturally explained by the importance of networks and acquaintanceships in China, 
known as 'guanxi'. Senior Danish genetics researchers have significant guanxi in China based on personal Chinese experiences of graduate education in Denmark.

There is a high degree of path-dependency in this explanation by networks and acquaintanceships, where previous relationships between individuals explain subsequent relationships between other individuals. Denmark is disadvantaged in the competition for outstanding young Chinese scientific talent especially compared to the USA. Existing guanxi of Danish academia with top Chinese professors and mentors is central for the recruitment of highly talented Chinese graduate students to Denmark.

These paths of scientific collaboration and recruitment can to a large extent be traced back to the graduate student experience of YANG Huangming in Copenhagen in the late 1980s and his very close and successful partnership with Lars Bolund of Aarhus University. YANG Huangming's subsequent outstanding success in Chinese and international genetics and his wish to work with and invest in Denmark is a major part of the background for the intense Sino-Danish interaction in genetics described in this paper. YANG Huangming has subsequently supervised and mentored Chinese students and junior colleagues to study in or work with Denmark. Interviews with these subsequent Chinese graduate students in Denmark suggest three to four 'generations' of mentor/mentee pairs.

The central finding of this study is, therefore, the importance of guanxi in high-level scientific collaboration between a small, highly developed country and China, under the necessary, but insufficient, condition of scientific quality in the small state. This guanxi reaches decades back in time and rests on recruiting outstanding Chinese graduate student talent for the small state.

The lesson for small, highly developed states wishing to engage in high-level scientific collaboration, talent circulation and funding with China is therefore to both ensure scientific quality and build science guanxi at as high levels as possible. Both are necessary, but insufficient, by themselves. For building 
high-level transnational science guanxi, it is paramount to attract as talented (graduate) students as possible and nurture long-term relationships with them.

Bernstein, T.P. 2010, China Learns from the Soviet Union, 1949-present, Lanham, Md. : Lexington Books.

Bertelsen, R.G., Du, X. \& Søndergaard, M.K. 2014, "Sino-Danish brain circulation: scholarship, capacity and policy", International Journal of Business and Globalisation, vol. 12, no. 2, pp. 142-160.

Bertelsen, R.G. \& Møller, S.T. 2010, The soft power of American missionary universities in China and of their legacies: St. John's University, Yale-in-China and Yenching University, Asia Research Centre, Copenhagen Business School, Copenhagen.

BGI 2012a, , Introduction of BGI Americas [Homepage of BGI], [Online]. Available: http://www.genomics.cn/en/navigation/show_navigation?nid=4175 [2012, 08/06].

BGI 2012b, , Introduction of BGI-Asia Pacific [Homepage of BGI], [Online]. Available: http://www.genomics.cn/en/navigation/show_navigation?nid=4177 [2012, 08/06].

BGI 2012c, , Introduction of BGI-Europe [Homepage of BGI], [Online]. Available: http://www.genomics.cn/en/navigation/show_navigation?nid=4176 [2012, 08/06].

BGI 2012d, , Introduction of BGI-Hong Kong [Homepage of BGI], [Online]. Available: http://www.genomics.cn/en/navigation/show_navigation?nid=4179 $[2012,08 / 06]$.

BGI 2012e, , Introduction of BGI-Japan [Homepage of BGI], [Online]. Available: http://www.genomics.cn/en/navigation/show_navigation?nid=4178 [2012, 08/06].

Cao, C., Suttmeier, R.P. \& Simon, D.F. 2009, "Success in state-directed innovation? Perspectives on China's plan for the development of science and technology" in The new Asian innovation dynamics: China and India in perspective, eds. G. Parayil \& A.P. D'Costa, Palgrave Macmillan, Basingstoke, UK; New York, NY, pp. 247-264.

Dana, L. 2014, Asian models of entrepreneurship - From the Indian Ocean and Nepal to the Japanese archipelago: Context, policy and practice, 2nd edn, World Scientific, London, Singapore.

Danish National Research Foundation nd, , Danish-Chinese Research Centers [Homepage of Danish National Research Foundation], [Online]. Available: http://dg.dk/en/other-fundingmechanisms/danish-chinese-research-centers/danish-chinese-research-centers/ [2015, 04/12].

DeVoretz, D. \& Zweig, D. 2008, "An Overview of Twenty-first-century Chinese "Brain Circulation"", Pacific Affairs, vol. 81, no. 2, pp. 171-173.

Gao, C. 2014, "The capitalisation of guanxi and Chinese entrepreneurship: an ethnographic study of petty entrepreneurs in Guangzhou, China", International Journal of Entrepreneurship and Small Business, vol. 23, no. 1-2: Special Issue "Innovative Entrepreneurial Endeavours Embedded in Culture", pp. 27-43. 
Huang, C., Gouveia, J.J.B. \& Varum, C.A. 2007, China: building an innovative economy, Chandos Publishing, Oxford.

Institute of International Education 2014, , Top 25 Places of Origin of International Students, 2012/132013/14 [Homepage of Institute of International Education], [Online]. Available: http://www.iie.org/opendoors [2015, 04/12].

Institute of International Education 2011, Open Doors 2011, Institute of International Education, Washington, DC.

Jensen, K. 2002, Bekcempelse af infektionssygdomme: Statens Serum Institut 1902-2002, Statens Serum Institut, København.

Kragh, H. 2001, "Henrik Dam - Nobelprismodtager og ernæringsforsker", Biozoom, , no. 1.

Kuah-Pearce, K.E., Rezaei, S. \& Schøtt, T. 2014, "Editorial", International Journal of Entrepreneurship and Small Business, vol. 23, no. 1-2: Special Issue "Innovative Entrepreneurial Endeavorrs Embedded in Culture", pp. 1-10.

Kure, B., Rasmussen, K. \& Bechsbøft, D. , Internationalt tilbageblik: 30 års arbejde med kulturaftaler [Homepage of Undervisningsministeriet], [Online]. Available: http://udd.uvm.dk/199803/udd3$\underline{11 . h t m}[2012,03 / 23]$.

Larsen, H.K. 2009, "Indvandrer, iværksætter, pioner: Bogen bag kineseren bag Daloon-eventyret", Kinabladet, vol. 43, no. Efterår, pp. 14-15.

Lundvall, B., Gu, S., Liu, J., Schwaag Serger, S. \& Malerba, F. 2009, "China's System and Vision of Innovation: An Analysis in Relation to the Strategic Adjustment and the Medium- to Long-Term S\&T Development Plan (2006-20)", Industry and Innovation.16, vol. 16, no. 4-5, pp. 369-388.

Lutz, J.G. 1971, China and the Christian Colleges 1859-1950, Cornell University Press, New York.

Ministry of Higher Education and Science 2013, , Global Cooperation [Homepage of Ministry of Higher Education and Science], [Online]. Available: http://ufm.dk/en/research-and-innovation/internationalcooperation/global-cooperation [2015, 04/12].

Pixiegene , PixieGENE AS [Homepage of Pixiegene], [Online]. Available: http://www.pixiegene.com/ [2013, 02/04].

Saxenian, A. 2006, The new argonauts: regional advantage in a global economy, Harvard University Press, Cambridge, MA.

Saxenian, A. "The international mobility of entrepreneurs and regional upgrading in India and China" in, pp. 117-144.

Saxenian, A. 2005, "From brain drain to brain circulation: transnational communities and regional upgrading in India and China", Studies in Comparative International Development, vol. 40, no. 2, pp. 35-61. 
Saxenian, A. \& Sabel, C. 2008, "Roepke Lecture in Economic Geography Venture Capital in the 'Periphery': The New Argonauts, Global Search, and Local Institution Building", Economic Geography, vol. 84, no. 4, pp. 379-394.

Schaaper, M. 2009, Measuring China's innovation system: national specificities and international comparisons, OECD Publishing.

Sino-Danish Breast Cancer Research Centre nd, , Sino-Danish Breast Cancer Research Centre [Homepage of Sino-Danish Breast Cancer Research Centre], [Online]. Available: http://www.bcrc.dk [2015, 04/12].

Statsministeriet nda, , Mфdemateriale fra Globaliseringsrådet 2005-2006 [Documents from meetings in the Globalization Commission 2005-2006] [Homepage of Statsministeriet], [Online]. Available: http://www.stm.dk/_p_13631.html [2015, 04/12].

Statsministeriet ndb, , Regerings globaliseringsstrategi: "Fremgang, fornyelse og tryghed" [The globalization strategy of the government: "Progress, renewal, and social safety"] [Homepage of Statsministeriet], [Online]. Available: http://stm.dk/_p_6685.html [2015, 04/09].

Tamm, D. 2009, "Ligger godt i maven...": Beretningen om S.C. Van, Daloons grundlagger, S.C. Van, Nyborg.

Wang, H., Zweig, D. \& Lin, X. 2011, "Returnee entrepreneurs: impact on China's globalization process", Journal of Contemporary China, vol. 20, no. 70, pp. 413-431.

Wang, Z. "Transnational Science during the Cold War: The Case of Chinese/American Scientists", Isis, vol. 101, no. 2, pp. 367-377.

West, P. 1976, Yenching University and Sino-Western Relations, 1916-1952, Harvard University Press, Cambridge, MA.

Wiegand, B. 2011, Udflytning af vidensjob skaber vakst i Danmark [Outsourcing of knowledge jobs creates growth in Denmark].

Zhang, F. 2015, "Building Biotech in Shanghai: A Perspective of Regional Innovation System", European Planning Studies, vol. 23, no. 10, pp. 2062-2078.

Zweig, D. 2006, "Competing for talent: China's strategies to reverse the brain drain", International Labour Review, vol. 145, no. 1/2, pp. 65.

Zweig, D. 1997, "To return or not to return? Politics vs. economics in China's brain drain", Studies in Comparative International Development, vol. 32, no. 1, pp. 92-125.

Zweig, D., Changgui, C. \& Rosen, S. 2004, "Globalization and Transnational Human Capital: Overseas and Returnee Scholars to China", The China Quarterly, , no. 179, pp. pp. 735-757. 